\title{
Embodied Conversational Agents for Patients With Dementia: Thematic Literature Analysis
}

Margherita Rampioni ${ }^{1}$, PsyD, PhD; Vera Stara ${ }^{1}$, PhD; Elisa Felici ${ }^{1}$, PsyD; Lorena Rossi ${ }^{1}$, MSc; Susy Paolini ${ }^{2}$, PsyD

${ }^{1}$ Model of Care and New Technologies, IRCCS INRCA - National Institute of Health and Science on Aging, Ancona, Italy

${ }^{2}$ Unit of Neurology, IRCCS INRCA - National Institute of Health and Science on Aging, Ancona, Italy

Corresponding Author:

Vera Stara, $\mathrm{PhD}$

Model of Care and New Technologies

IRCCS INRCA - National Institute of Health and Science on Aging

via Santa Margherita, 5

Ancona, 60124

Italy

Phone: 390718004614

Email: v.stara@inrca.it

\section{Abstract}

Background: As the world's population rapidly ages, the number of older adults with cognitive impairment will also increase. Several studies have identified numerous complex needs of people with dementia, which assistive technologies still fail to support. Recent trends have led to an increasing focus on the use of embodied conversational agents (ECAs) as virtual entities able to interact with a person through natural and familiar verbal and nonverbal communication. The use of ECAs could improve the accessibility and acceptance of assistive technologies matching those high-level needs that are not well covered to date.

Objective: The aim of this thematic literature analysis was to map current studies in the field of designing ECAs for patients with dementia in order to identify the existing research trend and possible gaps that need to be covered in the near future. The review questions in this study were as follows: (1) what research frameworks are used to study the interaction between patients with dementia and ECAs? (2) what are the findings? and (3) what are the barriers reported in these studies?

Methods: Separate literature searches were conducted in PubMed, Web of Science, Scopus, and Embase databases by using specific umbrella phrases to target the population (patients with dementia) and the technology-based intervention (embodied conversational agent). Studies that met the inclusion criteria were appraised through the Mixed Methods Appraisal Tool and then discussed in a thematic analysis.

Results: The search process identified 115 records from the databases and study references. After duplicates ( $\mathrm{n}=45$ ) were removed, 70 papers remained for the initial screening. A total of 7 studies were finally included in the qualitative synthesis. A thematic analysis of the reviewed studies identified major themes and subthemes: the research frameworks used to gather users' perspectives on ECAs (theme 1), the insights shared by the 7 studies as well as the value of user involvement in the development phases and the challenge of matching the system functionalities with the users' needs (theme 2), and the main methodological and technical problems faced by each study team (theme 3 ).

Conclusions: Our thematic literature analysis shows that the field of ECAs is novel and poorly discussed in the scientific community and that more sophisticated study designs and proofs of efficacy of the approach are required. Therefore, by analyzing the main topic of the narrative review, this study underscores the challenge of synchronizing and harmonizing knowledge, efforts, and challenges in the dementia care field and its person-centered paradigm through the user-centered design approach. Enabling strict collaboration between interdisciplinary research networks, medical scientists, technology developers, patients, and their formal and informal caregivers is still a great challenge in the field of technologies for older adults.

(JMIR Mhealth Uhealth 2021;9(7):e25381) doi: 10.2196/25381

\section{KEYWORDS}

dementia; patient with dementia; older adults with dementia; embodied conversational agent; virtual personal assistant; virtual agent; virtual companion; design for older adults; patients; elderly; virtual; personal assistant; cognitive; cognitive impairment 


\section{Introduction}

\section{Background}

The world's population is rapidly aging and approximately 47 million people are now experiencing dementia worldwide. This number could triple by 2050 with an incremental estimated cost that will range from US \$818 billion in 2015 to US \$2 trillion by 2030 [1]. Dementia is characterized by the progressive deterioration of both cognitive and functional abilities that affect a person's capability to perform everyday activities [2,3]. Nowadays, the tendency to view dementia solely within a medical framework is overcome through a new personhood paradigm based on the identification of the numerous complex needs of patients with dementia as described by Maslow [4] and Kitwood [5]. There is consensus that individuals living independently [6] or in long-term care [7-9] are able to express needs [10] and preferences [11] consistently, even in the advanced stage of dementia [12].

Since the challenges of responding to the growing number of people with dementia and their complex needs are substantial for governments [13], the field of assistive technologies is receiving more and more interest. In aged care, the term "assistive technology" refers to any device, product, or equipment that helps people to perform a task they would otherwise be unable to do or that facilitates older adults' activities of daily living [14]. In dementia care, assistive technologies (ie, technologies for daily living, meaningful and pleasurable activities and health care) can compensate for cognitive impairment, improve quality of life, favor autonomy, enable people to remain in their homes for longer, and reduce care costs [15-19]. Actually, a broad spectrum of technologies supports community-dwelling persons with dementia. These technologies mostly address basic physiological and safety needs, whereas little attention is devoted to higher-level needs such as self-esteem, quality of life, recreational activities or contrast behavioral issues, for example, aggression and mood changes [6,20-22]. Recently, several studies [23-27] proposed the use of screen-based entities designed to stimulate human face-to-face conversation skills called as embodied conversational agents (ECAs) or personal virtual assistants $[28,29]$. Such virtual entities are able to interact with a person through verbal and nonverbal communication. There is a significant and growing list of use cases for ECAs targeting older adults with or without cognitive impairment or their caregivers [15]: virtual coaches [30], virtual companions [31-33], personal virtual assistants [26], virtual butlers [34,35], and training tools to help formal and informal caregivers [36].

The use of ECAs could improve the accessibility and acceptance of computer-based assistive technologies when compared to graphical user and voice interfaces, especially for older adults with cognitive impairment [37-39], thus matching those high-level needs that are not satisfactorily covered by assistive technologies. The extent to which this specific innovation may be able to support people affected by dementia along the progressive nature of the disease represents a great challenge for the entire scientific community. Unfortunately, it seems that research in that specific direction is still poor and little is known on how patients with dementia interact with ECAs and how this interaction should be designed and managed by the system [15]. Therefore, to bridge this gap, this paper discusses the implications derived from a thematic literature review of the available studies focusing on personal virtual assistants in favor of patients with dementia.

\section{Aim of This Study}

The aim of this thematic literature analysis was to map current studies in the field of designing ECAs for patients with dementia in order to identify the existing research trends and possible gaps that need to be covered in the near future. The review questions were (1) what research frameworks are used to study the interaction between patients with dementia and ECAs? (2) what are the findings? and (3) what are the barriers reported in these studies?

\section{Methods}

\section{Design of This Study}

Separate literature searches were conducted in PubMed, Web of Science, Scopus, and Embase databases by using the following umbrella phrases to target the population and the specific technology-based intervention: ("patient with dementia" OR "people with dementia" OR "person with dementia") AND ("virtual agent" OR "personal virtual assistant" OR "virtual companion" OR "embodied conversational agent"). Inclusion criteria were published papers written in English with the aim of studying the use of ECAs (1) among older adults ( $\geq 65$ years) with dementia living at home, in long-term care, or nursing homes and their formal and informal caregivers, (2) for coping in patients with dementia without any restriction in terms of service applications (ie, cognitive games, reminders, medicine intake, calendar, etc), (3) for presenting empirical findings about interactions between users and ECAs, and (4) in randomized controlled trials (qualitative, quantitative, and the mixed methods approach were included). There was no restriction on publication dates, and the searches were finalized in July 2020. Papers were excluded if reviews, theoretical or technical studies, and contributions were not original research papers that met the inclusion criteria or were not written in English. According to predefined criteria, the screening phase was based on the analysis of titles and then abstracts. Later, full texts of those titles/abstracts of screened publications were reviewed independently by the first and the corresponding author in August 2020. Another researcher was involved in reaching consensus in cases of disagreement. Studies that met the inclusion criteria were included, and the results of the searches were summarized. Then, we performed a manual thematic analysis of the findings. We used the Preferred Reporting Items for Systematic Reviews and Meta-Analysis [40] flowchart in the retrieval and selection process (Figure 1, Multimedia Appendix 1). 
Figure 1. Flow diagram of the studies included in the thematic review as well as the main reasons for rejection.

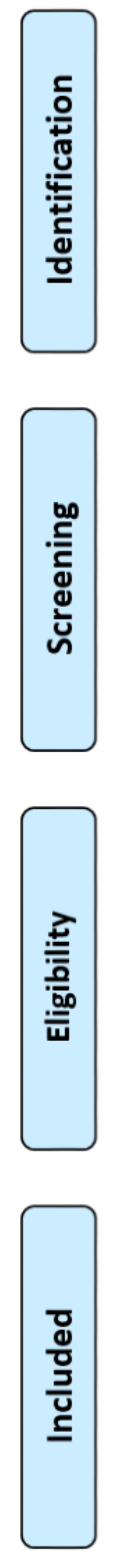

\section{Quality Appraisal}

Three authors independently appraised the final papers for their methodological quality by using the Mixed Methods Appraisal Tool version 2018 [41]. The Mixed Methods Appraisal Tool assesses the quality of qualitative, quantitative, and mixed methods studies and can be used to appraise the quality of different study designs. Precisely, it focuses on the methodological criteria and includes 5 core quality criteria for qualitative, randomized controlled, nonrandomized, quantitative descriptive, and mixed methods. Owing to these advantages, it was chosen over other tools prior to starting the narrative review. The results of each appraisal were compared, and any disagreement was solved through the intervention of the last author and discussion among the authors. According to the scoring system proposed by Pluye et al [42], a quantitative appraisal score was calculated by assessing the presence/absence of criteria (yes/no). The quality score was calculated as a percentage by using the formula: (number of "yes" responses divided by the number of appropriate criteria) $\times 100$.

\section{Thematic Analysis}

A thematic analysis was conducted to identify themes based on the 6 phases described by Braun and Clarke [43]. Themes were coded based on our specific review questions by following these steps: first, authors read the data from each study; and second, the corresponding author carried out a systematic manual coding of the features that led to initial codes before searching for themes in the third step. Themes were then reviewed for correlation with codes and the identification of subthemes during the fourth phase. After defining the themes in phase five, findings were evaluated for relevance to the research questions. Finally, the authors discussed the analysis process and reached consensus on the labelling.

\section{Results}

\section{Reviewed Studies}

The search process identified 95 records from the databases and an additional 20 by manually searching those studies' references. 
After duplicates $(n=45)$ were removed, 70 papers remained for initial screening by title. This resulted in 37 potentially eligible abstracts. The abstracts retained were analyzed by authors according to the research questions in order to obtain the final list of full-text papers to be reviewed. After the analysis of the abstracts, 33 of them were excluded as they did not fit the settled criteria of the target population and the specific technology-based intervention. A second screening step was performed for those full-text papers that matched all the criteria $(n=19)$. From this process, 12 papers were excluded because (1) studies recruited both patients with dementia and older adults in good health status $(n=3),(2)$ no empirical feedback from users was reported $(n=3)$, (3) the intervention was performed using both ECAs and other technologies $(n=2)$, and (4) the intervention was not specific for patients with dementia $(n=4)$. Finally, a total of 7 studies were included.

A summary of the studies and their findings are presented in Table 1. The 7 studies were conducted in Spain [24], Japan [27], France [15,44], Canada [45], Italy, and Luxembourg [46,47] and published between 2008 and 2019. They were heterogeneous in terms of objectives, population, contexts, and methodologies. Four of the 7 studies describe the development of 2 specific agents: Louise [15,44] and Anne [46,47].

The different agents are shown in Figure 2. Carrasco et al [24] built a prototype that included a tool for real-time streaming of a realistic avatar, previously programmed by a caregiver, to a television. This technique was used to simulate a true virtual assistant on the television screen. The avatar has a realistic voice and the lips are in synchronization with its speech to ensure that its facial movements appear natural. Yasuda et al [27] developed an agent conversation system shown on a computer screen in the form of an animated face resembling a 5-year-old grandchild. This system can detect the end of the speech sound of a subject's reply to a question and begins asking the next question. When the subject speaks, the agent reacts by automatically generating nods, mouth movements, and acknowledgments. Wargnier et al $[15,44]$ proposed a prototype of a semiautomatic system that allows the animation of a female cartoon-like character called Louise and speech synthesis from text. The character, displayed on either a computer screen or a television set, is in an idle pose and moves its lips while speaking. This system includes attention monitoring and interaction management based on a predefined script and keyboard inputs of a (presumably hidden) operator. Konig et al [45] developed an emotionally intelligent cognitive assistant in the form of a humanoid female character that shows up on a screen in an inactive pose. de Jong et al [46] and Stara et al [47] shared the know-how gained in the design and adaptation of the personal virtual assistant Anne, which is a friendly, female human-looking avatar talking and interacting with users on a screen. Older adults can communicate with the ECA through voice and touch. This system is able to learn autonomously from its users and gets to know their personal preferences and needs. 
Table 1. Summary of the reviewed studies.

\begin{tabular}{|c|c|c|c|c|c|c|}
\hline Studies & Purpose & Type of system & $\begin{array}{l}\text { Method for data col- } \\
\text { lection }\end{array}$ & Sample & $\begin{array}{l}\text { Country, test set- } \\
\text { ting }\end{array}$ & Findings \\
\hline $\begin{array}{l}\text { Carrasco et } \\
\text { al [24] }\end{array}$ & $\begin{array}{l}\text { To validate a func- } \\
\text { tional prototype that } \\
\text { gives a measure on } \\
\text { how natural the inter- } \\
\text { action between } \\
\text { avatars and people } \\
\text { with Alzheimer dis- } \\
\text { ease is. } \\
\text { To increase the ac- } \\
\text { ceptability of the } \\
\text { system by target } \\
\text { users }\end{array}$ & $\begin{array}{l}\text { Avatar displayed on } \\
\text { a standard television } \\
\text { set }\end{array}$ & $\begin{array}{l}\text { Yes/No questions } \\
\text { and one-to-one obser- } \\
\text { vation }\end{array}$ & $\begin{array}{l}21 \text { persons had Alzheimer } \\
\text { disease, with a Global De- } \\
\text { terioration Scale [48] mea- } \\
\text { sure ranging from } 3 \text { to } 5 \\
\text { (from mild to moderate) }\end{array}$ & $\begin{array}{l}\text { Spain, day care } \\
\text { center }\end{array}$ & $\begin{array}{l}\text { All users engaged } \\
\text { naturally with the } \\
\text { avatar, understood } \\
\text { the information } \\
\text { conveyed by the } \\
\text { avatar, and an- } \\
\text { swered successful- } \\
\text { ly by means of the } \\
\text { television remote } \\
\text { control }\end{array}$ \\
\hline $\begin{array}{l}\text { Yasuda et } \\
\text { al [27] }\end{array}$ & $\begin{array}{l}\text { To investigate the } \\
\text { effectiveness of a } \\
\text { conversation system } \\
\text { based on an animat- } \\
\text { ed face of a child }\end{array}$ & $\begin{array}{l}\text { A computer screen } \\
\text { that shows an animat- } \\
\text { ed face of a child } \\
\text { agent }\end{array}$ & $\begin{array}{l}\text { Qualitative inter- } \\
\text { views }\end{array}$ & $\begin{array}{l}8 \text { older adults ( } 2 \text { males and } \\
6 \text { females) had mild } \\
\text { Alzheimer disease, with a } \\
\text { Mini-Mental State Exami- } \\
\text { nation [49] mean score of } \\
\text { 22.2. The average age was } \\
\text { 78.5 years. }\end{array}$ & Japan, hospital & $\begin{array}{l}\text { All users con- } \\
\text { versed with the } \\
\text { conversational } \\
\text { agent system and } \\
\text { enjoyed the conver- } \\
\text { sation. }\end{array}$ \\
\hline $\begin{array}{l}\text { Wargnier } \\
\text { et al [44] }\end{array}$ & $\begin{array}{l}\text { To collect design } \\
\text { guidelines to devel- } \\
\text { op a semiautomated } \\
\text { ECA }^{\text {a }} \text { prototype }\end{array}$ & $\begin{array}{l}\text { A semiautomated } \\
\text { cartoon like ECA } \\
\text { prototype that runs } \\
\text { on a standard person- } \\
\text { al computer with } \\
\text { Microsoft Windows }\end{array}$ & $\begin{array}{l}\text { Semiautomated } \\
\text { Wizard of Oz, video, } \\
\text { observation, open } \\
\text { interview, question- } \\
\text { naire }\end{array}$ & $\begin{array}{l}14 \text { specialists ( } 4 \text { males and } \\
10 \text { females) in assistive } \\
\text { technologies for older } \\
\text { adults or care professionals } \\
\text { (medical doctors and neu- } \\
\text { ropsychologists, mostly) }\end{array}$ & France, hospital & $\begin{array}{l}\text { All participants in } \\
\text { teracted naturally } \\
\text { with the ECA. } \\
\text { Most displayed } \\
\text { high levels of atten- } \\
\text { tion. Globally, the } \\
\text { feedbacks turned } \\
\text { out to be rather } \\
\text { positive. }\end{array}$ \\
\hline $\begin{array}{l}\text { Konig et al } \\
{[45]}\end{array}$ & $\begin{array}{l}\text { To identify affective } \\
\text { identities in patients } \\
\text { with dementia for } \\
\text { the design of cogni- } \\
\text { tive assistive tech- } \\
\text { nologies }\end{array}$ & $\begin{array}{l}\text { An intelligent cogni- } \\
\text { tive assistant in the } \\
\text { form of a humanoid } \\
\text { female character } \\
\text { shown on a screen }\end{array}$ & $\begin{array}{l}\text { Qualitative inter- } \\
\text { view }\end{array}$ & $\begin{array}{l}12 \text { older adult care home } \\
\text { residents ( } 5 \text { males and } 7 \\
\text { females) with Alzheimer } \\
\text { disease who showed cogni- } \\
\text { tive and functional impair- } \\
\text { ment to an extent that it } \\
\text { affected their autonomy in } \\
\text { performing certain com- } \\
\text { plex activities of daily liv- } \\
\text { ing and } 9 \text { associated care- } \\
\text { givers ( } 2 \text { males and } 7 \text { fe- } \\
\text { males). The average age of } \\
\text { the residents was } 84.5 \\
\text { years. }\end{array}$ & $\begin{array}{l}\text { Canada, Universi- } \\
\text { ty and Research } \\
\text { Institute for Ag- } \\
\text { ing }\end{array}$ & $\begin{array}{l}\text { Definition of user } \\
\text { requirements for } \\
\text { the design }\end{array}$ \\
\hline $\begin{array}{l}\text { Wargnier } \\
\text { et al [15] }\end{array}$ & $\begin{array}{l}\text { To conduct a usabili- } \\
\text { ty study to refine } \\
\text { and validate the } \\
\text { Louise ECA }\end{array}$ & $\begin{array}{l}\text { A semiautomated } \\
\text { cartoon like ECA } \\
\text { prototype that runs } \\
\text { on a standard person- } \\
\text { al computer under } \\
\text { Microsoft Windows }\end{array}$ & $\begin{array}{l}\text { Realistic assistive } \\
\text { scenarios and } \\
\text { semistructured inter- } \\
\text { view }\end{array}$ & $\begin{array}{l}14 \text { participants ( } 3 \text { males } \\
\text { and } 11 \text { females) with mild } \\
\text { cognitive impairment } \\
\text { (9/14) or Alzheimer dis- } \\
\text { ease (5/14), whose Mini- } \\
\text { Mental State Examination } \\
\text { [49] scores ranged from } 8 \\
\text { to } 30 \text { (mean } 23.8, \text { SD } 4.9 \text { ). } \\
\text { The average age was } 78.8 \\
\text { years. }\end{array}$ & $\begin{array}{l}\text { France, hospital } \\
\text { and University }\end{array}$ & $\begin{array}{l}\text { Most of the partici- } \\
\text { pants were able to } \\
\text { interact with the } \\
\text { ECA, succeeded in } \\
\text { completing the } \\
\text { proposed tasks, } \\
\text { and enjoyed the } \\
\text { design }\end{array}$ \\
\hline $\begin{array}{l}\text { de Jong et } \\
\text { al [46] }\end{array}$ & $\begin{array}{l}\text { Report the first itera- } \\
\text { tion of a comprehen- } \\
\text { sive user-centered } \\
\text { development process } \\
\text { of virtual agents for } \\
\text { patients with demen- } \\
\text { tia and their care- } \\
\text { givers }\end{array}$ & $\begin{array}{l}\text { A personal assistant } \\
\text { called Anne that } \\
\text { works on a Surface } \\
\text { Pro tablet under the } \\
\text { Microsoft Windows } \\
10 \text { operating system }\end{array}$ & Focus group & $\begin{array}{l}16 \text { caregivers: } 10 \text { in Lux- } \\
\text { embourg ( } 6 \text { qualified nurs- } \\
\text { ing assistants and } 4 \text { infor- } \\
\text { mal carers) and } 6 \text { in Italy } \\
\text { ( } 3 \text { care professionals and } \\
3 \text { informal caregivers) }\end{array}$ & $\begin{array}{l}\text { Luxembourg, } \\
\text { Italy, hospital, } \\
\text { day care center }\end{array}$ & $\begin{array}{l}\text { Definition of user } \\
\text { requirements for } \\
\text { the design }\end{array}$ \\
\hline
\end{tabular}




\begin{tabular}{|c|c|c|c|c|c|c|}
\hline Studies & Purpose & Type of system & $\begin{array}{l}\text { Method for data col- } \\
\text { lection }\end{array}$ & Sample & $\begin{array}{l}\text { Country, test set- } \\
\text { ting }\end{array}$ & Findings \\
\hline $\begin{array}{l}\text { Stara et al } \\
{[47]}\end{array}$ & $\begin{array}{l}\text { How patients xperi- } \\
\text { ence a personal virtu- } \\
\text { al assistant in the } \\
\text { stage of moderate } \\
\text { dementia; how a } \\
\text { personal virtual assis- } \\
\text { tant can be modified } \\
\text { to the requirements } \\
\text { of people in the } \\
\text { stage of moderate } \\
\text { dementia }\end{array}$ & $\begin{array}{l}\text { A personal assistant } \\
\text { called Anne that } \\
\text { works on a Surface } \\
\text { Pro tablet under the } \\
\text { Microsoft Windows } \\
10 \text { operating system }\end{array}$ & $\begin{array}{l}\text { Protected environ- } \\
\text { ment test scenarios } \\
\text { with observation of } \\
\text { the interactions be- } \\
\text { tween patients and } \\
\text { the personal virtual } \\
\text { assistant and inter- } \\
\text { view to formal care- } \\
\text { givers }\end{array}$ & $\begin{array}{l}5 \text { female patients with } \\
\text { moderate dementia and } 2 \\
\text { formal caregivers in Italy; } \\
1 \text { female patient with de- } \\
\text { mentia and } 2 \text { formal care- } \\
\text { givers in Luxembourg }\end{array}$ & $\begin{array}{l}\text { Italy, Luxem- } \\
\text { bourg, hospital, } \\
\text { day care center }\end{array}$ & $\begin{array}{l}\text { Definition of user } \\
\text { requirements for } \\
\text { the design }\end{array}$ \\
\hline
\end{tabular}

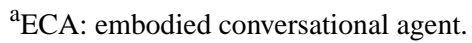

Figure 2. Embodied conversational agents described in the reported studies. A) Carrasco et al [24]; B) Yasuda et al [27]; C) Wargnier et al [15,44]; D) Konig et al [45]; E) de Jong et al [46] and Stara et al [47].

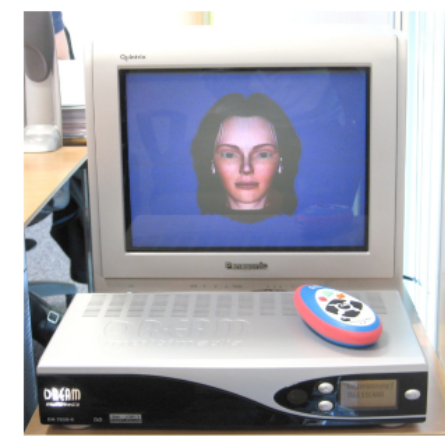

A

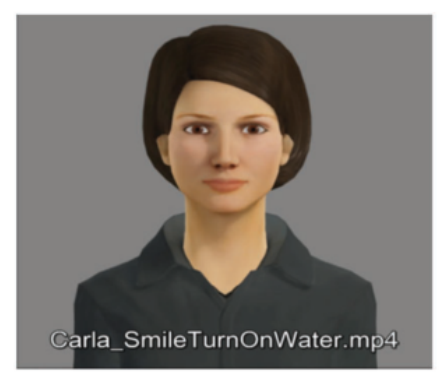

D

\section{Quality Appraisal of the Selected Studies}

The design of the 7 research studies was assessed by using screening questions and the 5 criteria of the Mixed Methods Appraisal Tool [41] for qualitative and mixed methods studies

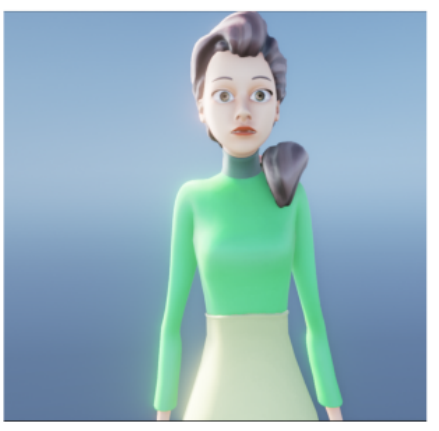

C

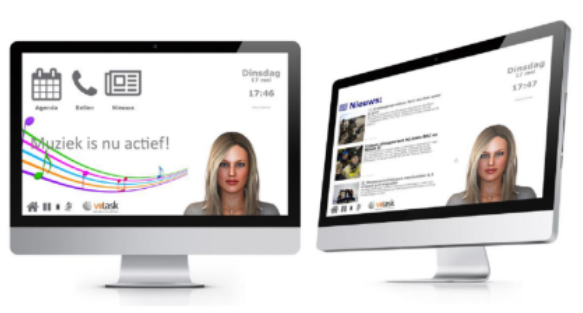

$E$

reported in Textbox 1: (1) appropriateness of objective/research question, (2) adequacy of the qualitative approach/method, (3) adequate gathering of findings from data, (4) sufficient interpretation of results from data, and (5) coherence between qualitative data sources, collection, analysis, and interpretation. 
Textbox 1. Mixed Methods Appraisal Tool version 2018 criteria to appraise the study design.

\author{
Methodological quality criteria \\ Screening questions (for all types) \\ $\mathrm{S} 1$. Are there clear research questions? \\ S2. Do the collected data allow to address the research questions? \\ Qualitative \\ Q1. Is the qualitative approach appropriate to answer the research question? \\ Q2. Are the qualitative data collection methods adequate to address the research question? \\ Q3. Are the findings adequately derived from the data? \\ Q4. Is the interpretation of results sufficiently substantiated by data? \\ Q5. Is there coherence between qualitative data sources, collection, analysis, and interpretation?

\section{Mixed methods} \\ M1. Is there an adequate rationale for using a mixed methods design to address the research question? \\ M2. Are the different components of the study effectively integrated to answer the research question? \\ M3. Are the outputs of the integration of qualitative and quantitative components adequately interpreted? \\ M4. Are divergences and inconsistencies between quantitative and qualitative results adequately addressed? \\ M5. Do the different components of the study adhere to the quality criteria of each tradition of the methods involved?
}

All the studies used appropriate research design, taking into account the research questions and problems related to the use of a specific innovation technology among persons with dementia. The prevalent data collection methods were open or semistructured interviews [15,27,45,47], observations $[24,44,47]$, a questionnaire [24,44], and a focus group [46]. The findings and interpretations of the results were coherent with data sources, collection, analysis, and discussion in all the studies. According to Pluye et al [42], the score for each study was calculated and then synthetized using 3 different categories: low score, $<35 \%$; medium score, $36 \%-70 \%$; and high score, $71 \%-100 \%$. All studies met the 5 quality criteria; therefore, the score calculation synthesized a high score of methodological quality results (Table 2).

Table 2. Quality scores of the selected studies.

\begin{tabular}{|c|c|c|c|c|c|c|c|}
\hline Studies & $\begin{array}{l}\text { Screening question } \\
\text { score }\end{array}$ & $\begin{array}{l}\text { Qualitative studies } \\
\text { score }\end{array}$ & $\begin{array}{l}\text { Mixed methods } \\
\text { studies score }\end{array}$ & $\begin{array}{l}\text { Total } \\
\text { score }\end{array}$ & $\begin{array}{l}\text { Appropriate criteria } \\
\text { (n) }\end{array}$ & $\begin{array}{l}\text { Quantity } \\
\text { score (\%) }\end{array}$ & Score category \\
\hline Carrasco et al [24] & 2 & $\mathrm{~N} / \mathrm{A}^{\mathrm{a}}$ & 5 & 7 & 7 & 100 & High \\
\hline Yasuda et al [27] & 2 & 5 & N/A & 7 & 7 & 100 & High \\
\hline Wargnier et al [44] & 2 & N/A & 5 & 7 & 7 & 100 & High \\
\hline Konig et al [45] & 2 & 5 & N/A & 7 & 7 & 100 & High \\
\hline Wargnier et al [15] & 2 & N/A & 5 & 7 & 7 & 100 & High \\
\hline de Jong et al [46] & 2 & 5 & N/A & 7 & 7 & 100 & High \\
\hline Stara et al [47] & 2 & 5 & N/A & 7 & 7 & 100 & High \\
\hline
\end{tabular}

${ }^{\mathrm{a}} \mathrm{N} / \mathrm{A}$ : not applicable.

\section{Thematic Analysis}

Following the analysis of reviewed studies, 3 major themes and subthemes within each theme were identified: (1) research frameworks, (2) efficacy of ECAs, (3) limitations of the studies and problems faced.

\section{Theme 1: Research Frameworks}

All the studies dealt with 2 research questions: (1) could virtual agent be a technology that patients with dementia can really use? and (2) which are the design features that can facilitate or hinder this usage? Methodologically, both qualitative and quantitative designs were applied to answer these questions focusing on meanings and understanding of experiences of people with dementia and their carers. In all cases, participants took part in the researches in participatory sessions or observations to avoid the discomfort of being the subjects of an experimental study. Overall, the 7 studies came to the general assumption that the use of ECAs is suitable for people with dementia. This common evidence based its foundation on the use of voice as an interaction modality between the systems. The voice as input/output modality is the natural and familiar way to engage people with dementia in such researches. Therefore, from 2008 to 2019, even though the readiness level 
of the virtual agents was changed considerably, especially in the human-looking appearance, none of the studies shared skepticism or disadvantages in the use of ECAs by the enrolled patients. Additionally, the use of common screen devices as the presentation platform on the television [24], computer $[15,27,44,45]$, or tablet [47] concur with the positive engagement of users. A notable consideration that emphasizes this outcome is the rigorous recruitment strategy followed by each team: as reported in Table 1, enrolled participants were previously diagnosed and scored on the Global Deterioration Scale [48] and the Mini-Mental State Examination [49]. Moreover, the experimental settings were always under the responsibility of researchers or formal caregivers in all the studies. However, the objectives of the 7 studies were different from the research question about which feature design could improve or impede the use of virtual characters. This is due, in part, to the specific purpose of each system under development that varied from natural interaction $[24,27,45]$ and their specificities $[15,44]$ to support independent living [46,47]. Features such as interaction paradigm and prompting style are seen as the main components that could be personalized and used for matching the needs and capabilities of users, thereby improving the user experience. Probably because the ECA field is still green, none of the studies pursued the general purpose to achieve general features design as the guidelines for future researches in the field.

\section{Theme 2: Efficacy of ECAs}

\section{Findings of the Selected Studies}

As previously mentioned, all the studies reported positive feedback on the use of agents by users: the majority of patients with dementia naturally interacted and responded to the virtual character fulfilling the assigned tasks [15,24,27,45]. The artificial assistant caught the attention of people, and in some cases, it was seen as a companion by older participants as well as formal and informal caregivers [46,47]. On the contrary, the preference of having a "real person helping me rather than a machine" [45] clearly showed the importance of a human contact. Moreover, participants with the most severe memory impairment frequently forgot how to interact with the system or talk to the ECA and it caused them some frustration or they seemed to be intimidated by the character [15]. These results are in line with the findings of the study conducted by Stara et al [47], who found that patients with moderate dementia spoke freely to the ECA without using the touch control. Persons with dementia generally had little experience with mobile technology before they became affected by dementia; therefore, patients seemed to have trouble using a touchscreen and navigating the different applications of the ECA. For that reason, formal caregivers involved in this research suggested a supervised usage of the virtual agent in a controlled environment such as daily centers. Formal caregivers were strongly convinced that their patients with moderate dementia could not use Anne independently at home. For them, ECAs could be useful tools for their daily working activities but only if controlled by professional staff. Nonetheless, positive results in terms of efficacy are reported in studies from the perspective of formal caregivers $[44,46,47]$. In particular, according to de Jong et al [46], virtual agents could help and support people with forgetful problems who are living independently in their homes.

\section{Value of a User-Driven Approach}

User-centered design as "a philosophy based on the needs and interests of the user, with an emphasis on making products usable and understandable" [50] is a common methodology involving end users during all iterations of the design process [51]. Four of the reviewed studies dealt with the development of the ECA through this user-driven approach: Louise [15,44] and Anne [46,47]. Louise was developed by adopting a co-design living lab approach involving older adults with dementia and stakeholders such as care professionals. The ECA called Anne [46,47] was developed using the umbrella framework of the ISO standard user-centered design [51] and providing a human-centered perspective through the active involvement of patients and their formal and informal caregivers. For us, this underlies key strengths to overcome the main barriers in applying technology for older adults in general and, in particular, for people who experience dementia. Therefore, Louise and Anne could be considered as good examples for the next generations of ECAs that will benefit from user-centered design by using input from users, patients, formal and informal caregivers as well as clinicians and other stakeholders. As reported by de Jong et al [46] and Konig et al [45], examining feedback from the point of view of family caregivers or other carers (ie, nurses, health care professionals, or care workers who work with persons with dementia) could build more awareness on how to develop effective technologies. This benefit can create better design, thus enhancing usability, user experience, acceptance, and potential market success. Nonetheless, how users come to accept and use the given technology was mainly explored by Wargnier et al [15] and Stara et al [47] who evaluated Louise's and Anne's usability and acceptance through direct observations. In addition, Carrasco et al [24] observed users during their interactions with the system and noted their observations in usability reports. None of the other studies reported in this narrative review mentioned information on the user-driven approach despite all the studies being clearly oriented to define the requirements definitions of the ECAs as a starting point of the development process. These requirements were analyzed to map functionalities and preferences for the next iterations. The user and technical requirements definitions are indeed the first actions of the user-centered design process [51].

\section{Matching Needs With Technology}

People with dementia have many changing needs during the progression of their disease, varying from memory support to almost all aspects of daily functioning. In these studies, specific ECA functions matched the physiological, comfort, and attachment needs. ECAs described in 3 of the included studies $[24,27,45]$ sought mainly to overcome the memory problems of persons with dementia, guide them in their daily activities, and meet their need for communication and social interaction. Memory problems are certainly a basic component of dementia, but communication, emotional, and behavioral problems represent significant issues too. The evolution of this disease can easily lead these people to refuse or forget to drink, eat, and take medication and to feel more alone, apathetic, and isolated. In these cases, the ECA could play a supporting role not only in helping patients to perform their daily activities more 
independently but also in stimulating dialogues and encouraging their participation in the conversation and, consequently, in maintaining social relationships. For example, in the study of Yasuda et al [27], a man with early onset dementia said, "In this system, I can talk freely without any hesitation or anxiety." This comment means that conversations with normal people were stressful to him owing to the difficulty of answering questions that he cannot reply to. As dementia severity progresses, depression and boredom increase as well as the sense of powerlessness, lack of control, and social withdrawal. For this reason, 4 of the reviewed studies [15,44,46,47] designed ECAs to meet multiple and more complex user needs. More precisely, in the studies on Louise [15,44] and Anne [46,47], the development of multi-purpose tools is described. The virtual agent Anne [46,47] offers some features such as reminder (personal and medication agenda), communication (video calls), information (news), and entertainment (games and music) that support users in all aspects of daily life. In particular, these features engage persons with dementia in various activities and help them pass the time in a more meaningful way and improve their quality of life. Louise $[15,44]$ proposes others features to patients such as guiding through a task, cognitive stimulation exercises, and attention management. In this latter case, the ECA aimed to compensate for users' attentional disorders by performing autonomous prompting (ie, calling the user to regain attention in case of distractions). In summary, these multi-purpose agents are able to engage persons with dementia both emotionally and motivationally and stimulate their attentional skills, thereby making them feel part of a larger project and therefore less apathetic and isolated. This engagement could increase the physical, cognitive, and emotional well-being of patients but this possibility is only postulated in the mapped studies.

\section{Theme 3: Limitations of These Studies and the Problems Faced}

Common limitations and problems are reported in the selected studies. The challenge of small samples is clearly mentioned even if they underwent the preliminary evaluation of the systems $[15,27,47]$. This limitation is strictly correlated to the willingness to involve the entire spectrum of dementia severity [15,46,47] in order to adapt the virtual agents to the changing needs of older patients through various stages of this illness. A problem that arose concerns the importance of personalized solutions [47]. For example, a specific personalized prompting style should be programmed reaffirming the user in his or her overall persona and situational identity [45]. This means that each user has different preferences that may influence adherence to the system. For instance, people who want the ECA to address them in a very polite manner may reject the ECA considering it disrespectful if it calls them by their first name and uses a personal pronoun [15]. In addition, with regard to pleasantness, in the study of Wargnier et al [44], all users expressed a positive or very positive opinion and more than half (7/13) said they would like to be able to personalize the character's appearance. Moreover, the ECA's prompting styles is another feature that needs to be adapted since patients with neutral valence and weaker identity profiles prefer to be less in control and, therefore, did not mind a dominating prompting style. On the other hand, users with identities that were positive and powerful reported they prefer to be in control over what happens to them, thus preferring more subtle prompts [45].

\section{Discussion}

\section{Principal Findings}

This review surveyed the literature on the usage of ECAs by patients with dementia with the aim to identify the current research trends and possible gaps to cover in the future. Three main questions piloted this study: (1) what research frameworks are used to study the interaction between persons with dementia and ECAs? (2) what are the findings? and (3) what are the barriers? Only 7 papers were returned from the search. Overall, the main findings of this narrative review demonstrate that research on ECAs as an innovative way to cope with dementia is little covered in the state of the art even though interesting topics emerged from the mapped studies: the research design used to perform such studies (theme 1), major findings, the value of a user-driven approach, the importance of a well-balanced matching between the system functionalities and the users' needs (theme 2), as well as the reported problems faced by each study team (theme 3 ). Therefore, this section will discuss the implications raised through the lens of each theme reported in this study.

By examining the research frameworks of studies included in this review, it clearly emerges that the use of ECAs deserves (1) a more sophisticated study design and (2) proof of the efficacy of the approach, as in any other technology designed for people with dementia. The key to managing both demands is to directly involve older adults with dementia in the design of services dedicated to them. The early engagement of users from the outset and across all stages of the development cycle is relevant for people affected by dementia, since they progressively lose the ability to generalize between past and present experiences or to modify cognitive representations. For this reason, familiarity with the technology to be used is to be firmly considered and needs to be carefully planned. Indeed, while healthy adults are easily able to manage routine changes such as introducing a new device into their home environment, for older adults with dementia, these novelties can become extremely distressing and disorientating. Moreover, different limitations can overburden users: limitations in knowledge and understanding of the technology and limitations in communication between the user and the technology. As discussed in themes 1 and 2, the use of a common television or computer screen and the possibility of using verbal response as an input/output mode enables a more natural way of interaction. This is a valuable benefit for people with mild and moderate dementia. According to Kaplan and Kaplan [52], familiarity is the relationship between an individual and something that this individual has had considerable experience with. The experience leads to the development of an internal model on how one expects something to work. Some of the included studies $[15,46,47]$ revealed that less familiarity (a low experience with new technologies) and greater dementia severity will almost certainly lead to greater difficulty in accessing technology and inevitable intervention of the caregiver who will have to spend 
additional time to teach and support persons with dementia in using a new tool. This is in line with the state of the art in this field [53-57]. In fact, familiarity helps in encouraging older adults to learn and understand how to interact with new technologies by using their existing knowledge. Moreover, considering that perceived difficulties become more pronounced as dementia severity increases, the ability of a system to adapt to the changing needs and capabilities of users will determine the successful implementation of this system in everyday use.

The concept of familiarity is not the only principle to follow in the field of designing ECAs for persons with dementia. In the last decade, we conceived the important shift to a model of care centered on the person, which broke the traditional disease-focused approach. Thanks to this new paradigm, care and support are seen as ways to prevent functional decline, frailty, and disability [58] and to create a multifunctional status (ie, intrinsic capacity) to follow up over time $[59,60]$. Therefore, when approaching technological solutions that enable older people to remain independent at home, it is decisive to embrace the same paradigm: a model of design that follows the same path of the model of care, giving value to the person's functions and needs [61-65]. Just as it is important to disseminate a model of care centered on the patients and their needs [66-68], it would be desirable to have a model of design that allows the participation of end users to propose more customized and consequently, more effective solutions. The benefits of a personalized design will spill over to end users who will achieve a higher level of well-being because they will see their needs met and caregivers whose burden will lighten. These concepts also emerged from some of the included studies [15,45-47] discussed in the theme 2. According to de Jong et al [46], persons with dementia cannot be treated as a homogeneous group and not in the same way. There is no "one right way" to take care of them, and one tool that will "fit all" cannot be created. Wargnier et al [15] also recommended a planning of technological strategies that consider the interpersonal variability of dementia and its evolution in time for each person. Moreover, Konig et al [45] underscored the importance of understanding past and current identities of persons with impaired cognitive abilities in technology-based efforts to provide individualized care and to suggest participatory design so that personalized solutions can be provided and the quality of life can be enhanced.

This new paradigm emphasizes the power of self-determination over decisions that affect the individual's body and mind. Therefore, the individual dignity and autonomy, which are the primary values and the fundamental rights of every human being, are restored. In this new vision, patients actively participate in clinical decisions outside the old schema of only being a sick person who needs to be treated. Nowadays, well-being is the goal of dementia care that offers individualized interventions and considers the person as a whole, thus considering individuals' medical, cognitive, psychological, environmental, cultural, and social needs [69]. Such individualized intervention can be co-designed with the direct involvement of patients. Co-designing creates a common knowledge base among designers, patients, and other stakeholders on the quality of life, pains, and gains and on how to support the remaining capabilities of persons with dementia [70]. The value of co-design is well recognized in all the studies reported in this narrative review. These considerations suggest that the field of new technologies such as ECAs needs to synchronize and harmonize knowledge, efforts, and challenges in the dementia care field and the new person-centered paradigm. For example, the respect of the principle of familiarity can promote the major involvement of people with dementia in the design of artifacts from the initial stage of the development process. Moreover, this engagement can also provide a sense of continuity for them, facilitating long-term use and acceptance of assistive devices along the disease's progression. At the same time, usage continuity could open up the possibility of recruiting bigger samples of patients for enrollment in high-quality scientific research frameworks, thereby overcoming the limitations reported in the theme 3 .

Another instance of harmonization is to focus on personhood and needs by clarifying what functionality and attributes are important in the new products for target users, what motivates them to use a product, what factors would hinder a positive user experience with a proposed product, and to conceptualize how parts of their lives could be improved by technology. Across the 3 themes analyzed in this review, the user experience of ECAs could be improved firstly by responding to the changing needs of people with dementia. This matching will enable technologies that better support the quality of life of people with dementia. This is particularly highlighted in the studies with more advanced ECAs such as Louise $[15,44]$ and Anne $[46,47]$. Moreover, as predominantly reported in the 7 research studies, technologies should be able to adapt to the reserved skills of people with dementia without discouraging people with dementia from engagement; therefore, the natural modality of interaction by voice and the use of common screen devices are significant features to enable positive user experience. Additionally, as argued in themes 1 and 3, features such as interaction paradigm and prompting style are seen as the main components that can be personalized and used for matching the needs and capabilities of users, thereby improving the user experience. To date, the predominant use of technological solutions for safety and security [22] needs to be overcome by embracing a new paradigm that offers innovation supporting higher-level needs such as belonging, self-esteem, identity, and self-actualization [6]. The use of ECAs could be the future response to these higher-level needs and the management of everyday life across the disease's journey. In any case, this approach seeks coordination between multidisciplinary teams composed of research elements, technology developers, health care communities, formal and informal caregivers, and primary users [6] as the core of the user-driven approach [51]. As reported in this narrative review, the significant valence of the user-centered design as well as the iterative measurements of the usability and acceptance rate are still milestones to achieve during the research and devolvement process of technologies for people with dementia.

\section{Comparison With Prior Works and Limitations}

To the best of our knowledge, no other narrative reviews are reported in the literature regarding the research frameworks used to study the interaction between persons with dementia 
and ECAs and between the mapped outcomes and barriers. Despite this positive aspect, there are some limitations to this review. Data sources were drawn from only 4 databases (ie, Scopus, Web of Science, PubMed, and Embase) and accessed only during a specific period of time (July 2020). The choice of using specific phrases to target the population ("patient with dementia" OR "people with dementia" OR "person with dementia") and the specific technology-based intervention ("virtual agent" OR "personal virtual assistant" OR "virtual companion" OR "embodied conversational agent") could have omitted some results from the search. It is possible that other literary sources were available in other unselected databases. However, well-known and broad-spectrum databases were used in this review. Moreover, we collected a relatively small sample of studies and excluded non-English language studies. Therefore, even if the 7 studies included in this paper were homogeneous in terms of their qualitative research design and their meeting our inclusion criteria, this may have created some biases. In addition, some authors of this review are co-authors in 2 of the reported studies $[46,47]$. Despite these limitations, our study offers several research directions, which may take the existing debates to the next level.

\section{Future of ECAs}

This review mapped the actual use of ECAs in the research field of dementia. The readiness level of this specific technology-based intervention grew across the years, shifting from to be initially displayed on a standard television set [24] and computer screen $[15,27,44,45]$ to mobile standalone solutions $[46,47]$. This led to important achievements in the visual representation as well as in the conversational abilities of the ECAs that technologically could be seen as the foundation for advanced applications in the near future as nontherapeutic interventions to assist individuals with dementia. However, despite these promising improvements over 12 years, it remains difficult to prove that ECAs are effective to mimic interpersonal communication when interacting with users and safe to use in the care practice. Technological advances in the embodiment, content, communication modality, and strategy are not indeed the only axes of improvement since there is still to discover how preferences regarding the appearance, animation, and personalized features can influence user acceptance and efficacy of the intervention. The scarcity of evaluation and implementation phase studies underlined the necessity for further research with larger sample sizes, suitable control groups, and clinical populations but the emerging interest on the field is a gaining advancement [71,72]. Anyway, possible steps forward for the use of such systems in health care delivery can be seen in integrated platform services. For example, telemedicine, ambient intelligence, and machine learning systems can be improved through conversational agents especially in the area of health counselling, coaching, psychotherapy, and self-monitoring. Additionally, interactions between virtual agents and advanced robotics is a new design challenge [73] that could embody ECAs in social robots enforcing the attention, facial expressions, and tone of voice of future human-like robots.

\section{Conclusions}

This narrative review summarizes the current research on ECAs for patients with dementia. Technologically, these artificial characters are very interesting and the mapped studies shared promising results in terms of engagement of patients. Unfortunately, until now, it has been difficult to prove that ECAs are effective and more efforts need to be spent to achieve to this evidence. Therefore, our thematic analysis reported on 3 main themes, namely, the research frameworks used to gather users' perspectives on ECAs (theme 1), the valuable insights shared by the 7 studies as well as the value of user involvement in the development phases and the challenge of matching the system functionalities with users' needs (theme 2), and the main methodological and technical problems faced by each study team (theme 3). It emerged that this specific field of research is novel and poorly discussed in the scientific community, but possible steps forward for the use of such systems in health care delivery are predictable. Moreover, analyzing the main metaphors across the studies, our work underscored the challenge to synchronize and harmonize knowledge, efforts, and challenges within the dementia care field and its person-centered paradigm. This can be effectively possible by adopting the well-known but still little used user-centered design [51] approach, which standardizes the compelling multidisciplinary vision of research and development of innovative technologies. The challenge is therefore to enable strict collaboration between interdisciplinary research networks, medical scientists, technology developers, patients, and their formal and informal caregivers.

\section{Acknowledgments}

This study is cofunded by the EU Active and Assisted Living Program (reference AAL-call-2016-102) and partially supported by Ricerca Corrente funding from the Italian Ministry of Health.

\section{Authors' Contributions}

VS and MR conceptualized and designed the study and drafted the manuscript. LR, EF, and SP analyzed the data and reviewed the manuscript. All authors provided intellectual contributions and critical feedback and reviewed the final manuscript.

\section{Conflicts of Interest}

None declared.

\section{Multimedia Appendix 1}

PRISMA checklist. 
[DOCX File, 22 KB-Multimedia Appendix 1]

\section{References}

1. The global dementia observatory reference guide. World Health Organization. URL: https://apps.who.int/iris/handle/10665/ $\underline{272669}$ [accessed 2021-07-15]

2. Arrighi HM, Gélinas I, McLaughlin TP, Buchanan J, Gauthier S. Longitudinal changes in functional disability in Alzheimer's disease patients. Int Psychogeriatr 2013 Jun;25(6):929-937. [doi: 10.1017/S1041610212002360] [Medline: 23406898]

3. Alzheimer's Association. Alzheimer's disease facts and figures. Alzheimer's \& Dementia 2020 Mar 10;16(3):391-460. [doi: 10.1002/alz.12068]

4. Maslow A. Motivation and Personality. 2nd edition. New York: Pearson; 1970.

5. Kitwood T. The experience of dementia. Aging \& Mental Health 1997 Feb;1(1):13-22. [doi: 10.1080/13607869757344]

6. Koo BM, Vizer LM. Examining Mobile Technologies to Support Older Adults With Dementia Through the Lens of Personhood and Human Needs: Scoping Review. JMIR Mhealth Uhealth 2019 Nov 11;7(11):e15122 [FREE Full text] [doi: 10.2196/15122] [Medline: $\underline{31710305]}$

7. Cadieux M, Garcia LJ, Patrick J. Needs of people with dementia in long-term care: a systematic review. Am J Alzheimers Dis Other Demen 2013 Dec;28(8):723-733 [FREE Full text] [doi: 10.1177/1533317513500840] [Medline: 24005852]

8. Milte R, Shulver W, Killington M, Bradley C, Ratcliffe J, Crotty M. Quality in residential care from the perspective of people living with dementia: The importance of personhood. Arch Gerontol Geriatr 2016;63:9-17 [FREE Full text] [doi: 10.1016/j.archger.2015.11.007] [Medline: 26791166]

9. Barker S, Board M. Dementia Care in Nursing. London: SAGE Publications; 2012.

10. von Kutzleben M, Schmid W, Halek M, Holle B, Bartholomeyczik S. Community-dwelling persons with dementia: what do they need? What do they demand? What do they do? A systematic review on the subjective experiences of persons with dementia. Aging Ment Health 2012;16(3):378-390. [doi: 10.1080/13607863.2011.614594] [Medline: 22250961]

11. Miller LM, Whitlatch CJ, Lyons KS. Shared decision-making in dementia: A review of patient and family carer involvement. Dementia (London) 2016 Sep;15(5):1141-1157. [doi: 10.1177/1471301214555542] [Medline: 25370075]

12. Whitlatch C, Menne H. Don't forget about me! Decision making by people with dementia. Generations. 2009. URL: https:/ /www.ingentaconnect.com/content/asag/gen/2009/00000033/00000001/art00011 [accessed 2021-07-15]

13. Dementia: a public health priority. World Health Organization. URL: https://apps.who.int/iris/handle/10665/75263 [accessed 2021-07-15]

14. Vichitvanichphong S, Talaei-Khoei A, Kerr D, Ghapanchi A. Adoption of Assistive Technologies for Aged Care: A Realist Review of Recent Studies. 2014 Presented at: Proceedings of the 47th Hawaii International Conference on System Sciences (HICSS); 2014; Hawaii p. 6-9.

15. Wargnier P, Benveniste S, Jouvelot P, Rigaud A. Usability assessment of interaction management support in LOUISE, an ECA-based user interface for elders with cognitive impairment. TAD 2018 Nov 26;30(3):105-126. [doi: 10.3233/tad-180189]

16. Malmgren Fänge A, Schmidt SM, Nilsson MH, Carlsson G, Liwander A, Dahlgren Bergström C, TECH@HOME Research Group. The TECH@HOME study, a technological intervention to reduce caregiver burden for informal caregivers of people with dementia: study protocol for a randomized controlled trial. Trials 2017 Feb 09;18(1):63 [FREE Full text] [doi: 10.1186/s13063-017-1796-8] [Medline: 28183323]

17. Ploeg J, McAiney C, Duggleby W, Chambers T, Lam A, Peacock S, et al. A Web-Based Intervention to Help Caregivers of Older Adults With Dementia and Multiple Chronic Conditions: Qualitative Study. JMIR Aging 2018 Apr 23;1(1):e2 [FREE Full text] [doi: 10.2196/aging.8475] [Medline: $\underline{\text { 31518230] }}$

18. Cahill S, Begley E, Faulkner J, Hagen I. "It gives me a sense of independence" - Findings from Ireland on the use and usefulness of assistive technology for people with dementia. TAD 2007 Apr 13;19(2-3):133-142. [doi:

10.3233/tad-2007-192-310]

19. Carrillo MC, Dishman E, Plowman T. Everyday technologies for Alzheimer's disease care: Research findings, directions, and challenges. Alzheimers Dement 2009 Nov;5(6):479-488. [doi: 10.1016/j.jalz.2009.09.003] [Medline: 19896587]

20. Lorenz K, Freddolino PP, Comas-Herrera A, Knapp M, Damant J. Technology-based tools and services for people with dementia and carers: Mapping technology onto the dementia care pathway. Dementia (London) 2019 Feb;18(2):725-741. [doi: 10.1177/1471301217691617] [Medline: 28178858]

21. Evans J, Brown M, Coughlan T, Lawson G, Craven M. A systematic review of dementia focused assistive technology. 2015 Presented at: Proceedings of the 17th International Conference on Human-Computer Interaction (HCI); August 2-7; Los Angeles, CA, USA p. 406-417.

22. Meiland F, Innes A, Mountain G, Robinson L, van der Roest H, García-Casal JA, et al. Technologies to Support Community-Dwelling Persons With Dementia: A Position Paper on Issues Regarding Development, Usability, Effectiveness and Cost-Effectiveness, Deployment, and Ethics. JMIR Rehabil Assist Technol 2017 Jan 16;4(1):e1 [FREE Full text] [doi: 10.2196/rehab.6376] [Medline: 28582262]

23. Morandell M, Hochgatterer A, Fagel S, Wassertheurer S. Avatars in assistive homes for the elderly: a user-friendly way of interaction? 2008 Presented at: Proceedings of the 4th Symposium of the Workgroup Human-Computer Interaction and Usability Engineering (HCI\&UE) of the Austrian Computer Society; November 20-21; Graz, Austria p. 391-402. 
24. Carrasco E, Epelde G, Moreno A, Ortiz A, Garcia I, Buiza C. Natural interaction between avatars and persons with Alzheimer disease. 2008 Presented at: Proceedings of the 11th International Conference on Computers Helping People with Special Needs (ICCHP); July 9-11; Linz, Austria p. 38-45.

25. Huang H, Matsushita H, Kawagoe K, Sakai Y, Nonaka Y, Nakano Y. Toward a memory assistant companion for the individuals with mild memory impairment. 2012 Presented at: Proceedings of the 11th IEEE International Conference on Cognitive Informatics and Cognitive Computing (ICCI*CC); January 2012; Kyoto, Japan p. 22-24.

26. Yaghoubzadeh R, Kramer M, Pitsch K, Kopp S. Virtual agents as daily assistants for elderly or cognitively impaired people. 2013 Presented at: Proceedings of the 13th International Workshop on Intelligent Virtual Agents (IVA); August 29-31; Edinburgh, UK p. 79-91.

27. Yasuda K, Aoe J, Fuketa M. Development of an agent system for conversing with individuals with dementia. 2013 Presented at: Proceedings of the 27th Annual Conference of the Japanese Society for Artificial Intelligence; June 4-7; Toyama, Japan.

28. Tsiourti C, Quintas J, Ben-Moussa M, Hanke S, Nijdam N, Konstantas D. The CaMeLi framework? A multimodal virtual companion for older adults. 2016 Presented at: Proceedings of SAI Intelligent Systems Conference (IntelliSys); September 21-22; London, UK p. 196-217.

29. Montenegro JLZ, da Costa CA, da Rosa Righi R. Survey of conversational agents in health. Expert Systems with Applications 2019 Sep;129:56-67 [FREE Full text] [doi: 10.1016/j.eswa.2019.03.054]

30. Bickmore TW, Silliman RA, Nelson K, Cheng DM, Winter M, Henault L, et al. A randomized controlled trial of an automated exercise coach for older adults. J Am Geriatr Soc 2013 Oct;61(10):1676-1683. [doi: 10.1111/jgs.12449] [Medline: 24001030]

31. Shibusawa S, Huang H, Hayashi Y, Kawagoe K. Toward a virtual companion for the elderly: exploring the behaviors that potentially achieve rapport in human communication. In: Cross-Cultural Design: Cultural Differences in Everyday Life. Berlin/Heidelberg: Springer; 2013:147-156.

32. Vardoulakis L, Ring L, Barry B, Sidner C, Bickmore T. Designing relational agents as long term social companions for older adults. 2012 Presented at: Proceedings of the 12th International Conference on Intelligent Virtual Agents (IVA); September 12-14; Santa Cruz, CA, USA p. 289-302.

33. Ring L, Barry B, Totzke K, Bickmore T. Addressing loneliness and isolation in older adults: proactive affective agents provide better support. 2013 Presented at: Proceedings of the 5th Humaine Association Conference on Affective Computing and Intelligent Interaction (ACII); September 2-5; Geneva, Switzerland p. 61-66.

34. Zancanaro M, Gabrielli S, Jameson A, Leonardi C, Not E, Pianesi F. Virtual helper or virtual card player? Contrasting responses of older users. In: Your Virtual Butler: The Making Of. Berlin/Heidelbergpringer: Springer-Verlag; 2013.

35. Fagel S, Hilbert A, Mor M, Mayer C. The virtual counselor automated character animation for ambient assisted living. 2013 Presented at: Proceedings of the 6th International Conference on Advances in Computer-Human Interactions (ACHI); February 24; Nice, France p. 184-187.

36. Maiden N, D'Souza S, Jones S, Müller L, Pannese L, Pitts K, et al. Computing technologies for reflective, creative care of people with dementia. Commun. ACM 2013 Nov;56(11):60-67. [doi: 10.1145/2500495]

37. Chittaro L, Ieronutti L, Rigutti S. Supporting presentation techniques based on virtual humans in educational virtual worlds. 2005 Presented at: Proceedings of the International Conference on Cyberworlds (CW); November; Singapore p. $245-252$.

38. Ortiz A, del Puy Carretero M, Oyarzun D, Yanguas J, Buiza C, Gonzalez M. Elderly users in ambient intelligence: does an avatar improve the interaction? 2006 Presented at: Proceedings of the 9th ERCIM Workshop on User Interfaces for All; September 27-28; Königswinter, Germany p. 99-114.

39. Bickmore T, Schulman D, Yin L. Maintaining Engagement in Long-term Interventions with Relational Agents. Appl Artif Intell 2010 Jul 01;24(6):648-666 [FREE Full text] [doi: 10.1080/08839514.2010.492259] [Medline: 21318052]

40. Moher D, Liberati A, Tetzlaff J, Altman DG, PRISMA Group. Preferred reporting items for systematic reviews and meta-analyses: the PRISMA statement. Phys Ther 2009 Sep;89(9):873-880. [Medline: 19723669]

41. Hong Q, Pluye P, Fàbregues S, Bartlett G, Boardman F, Cargo M. Mixed Methods Appraisal Tool (MMAT) version 2018. URL: http://mixedmethodsappraisaltoolpublic.pbworks.com/w/file/fetch/127916259/ MMAT 2018 criteria\%20manual 2018\%202008\%202001 ENG.pdf [accessed 2021-07-15]

42. Pluye P, Gagnon M, Griffiths F, Johnson-Lafleur J. A scoring system for appraising mixed methods research, and concomitantly appraising qualitative, quantitative and mixed methods primary studies in Mixed Studies Reviews. Int J Nurs Stud 2009 Apr;46(4):529-546. [doi: 10.1016/j.ijnurstu.2009.01.009] [Medline: 19233357]

43. Braun V, Clarke V. Using thematic analysis in psychology. Qualitative Research in Psychology 2006 Jan;3(2):77-101. [doi: 10.1191/1478088706qp063oa]

44. Wargnier P, Malaisé A, Jacquemot J. Towards attention monitoring of older adults with cognitive impairment during interaction with an Embodied Conversational Agent. 2015 Presented at: Proceedings of the 3rd IEEE International Workshop on Virtual and Augmented Assistive Technology (VAAT); March 23; Arles, France p. 23-28.

45. König A, Francis LE, Joshi J, Robillard JM, Hoey J. Qualitative study of affective identities in dementia patients for the design of cognitive assistive technologies. J Rehabil Assist Technol Eng 2017 Jan;4:2055668316685038 [FREE Full text] [doi: 10.1177/2055668316685038] [Medline: 31186921] 
46. de Jong M, Stara V, Von Döllen V, Bolliger D, Heerink M, Evers V. Users requirements in the design of a virtual agent for patients with dementia and their caregivers. 2018 Presented at: Proceedings of the 4th EAI International Conference on Smart Objects and Technologies for Social Good (Goodtechs); November 28-30; Bologna, Italy.

47. Stara V, de Jong M, Felici E, Bolliger D, Birrer E, von Döllen V. The design adaptation of the Virtual Assistant Anne for moderate dementia patients and their formal caregivers in protected environment tests. 2019 Presented at: Proceedings of the AHFE 2019 International Conference on Human Factors Ergonomics in Healthcare Medical Devices; July 24-28; Washington DC, USA p. 270-279.

48. Reisberg B, Ferris SH, de Leon MJ, Crook T. The Global Deterioration Scale for assessment of primary degenerative dementia. Am J Psychiatry 1982 Sep;139(9):1136-1139. [doi: 10.1176/ajp.139.9.1136] [Medline: 7114305$]$

49. Folstein MF, Folstein SE, McHugh PR. "Mini-mental state". A practical method for grading the cognitive state of patients for the clinician. J Psychiatr Res 1975 Nov;12(3):189-198. [doi: 10.1016/0022-3956(75)90026-6] [Medline: 1202204]

50. Norman D. The Design of Everyday Things. Cambridge, MA: MIT Press; 1998.

51. ISO 9241-210:2010 Ergonomics of human-system interaction-Part 210: Human-centered design for interactive systems. ISO. 2010. URL: https://www.iso.org/standard/52075.html [accessed 2021-07-12]

52. Kaplan S, Kaplan R. Cognition and Environment: Functioning in an Uncertain World. New York: Praeger; 1982.

53. Boger J, Craig T, Mihailidis A. Examining the impact of familiarity on faucet usability for older adults with dementia. BMC Geriatr 2013 Jun 20;13:63 [FREE Full text] [doi: 10.1186/1471-2318-13-63] [Medline: 23786533]

54. Burmeister OK. The development of assistive dementia technology that accounts for the values of those affected by its use. Ethics Inf Technol 2016 May 25;18(3):185-198. [doi: 10.1007/s10676-016-9404-2]

55. Holthe T, Halvorsrud L, Karterud D, Hoel K, Lund A. Usability and acceptability of technology for community-dwelling older adults with mild cognitive impairment and dementia: a systematic literature review. Clin Interv Aging 2018;13:863-886 [FREE Full text] [doi: 10.2147/CIA.S154717] [Medline: 29765211]

56. Teipel S, Babiloni C, Hoey J, Kaye J, Kirste T, Burmeister OK. Information and communication technology solutions for outdoor navigation in dementia. Alzheimers Dement 2016 Jun;12(6):695-707 [FREE Full text] [doi: 10.1016/j.jalz.2015.11.003] [Medline: 26776761]

57. Zhang H, Shen Z, Lin J, Chen Y, Miao Y. Familiarity design in exercise games for elderly. Int J Inf Technol. 2016. URL: https://www.ntulily.org/wp-content/uploads/journal/Familiarity Design in Exercise Games for Elderly accepted.pdf [accessed 2021-07-15]

58. Murray CJ, Lopez AD. Measuring the global burden of disease. N Engl J Med 2013 Aug 01;369(5):448-457. [doi: 10.1056/NEJMra1201534] [Medline: 23902484]

59. de Carvalho IA, Martin F, Cesari M, Summi Y, Thiyagarajan J, Beard J. Operationalising the concept of intrinsic capacity in clinical settings. In: Background papers of the WHO clinical consortium on healthy ageing. Geneva, Switzerland: World Health Organization; 2017 Presented at: WHO clinical consortium on healthy ageing; November 21-22; Geneva, Switzerland URL: https://www.who.int/ageing/health-systems/clinical-consortium/CCHA2017-backgroundpaper-1.pdf

60. WHO clinical consortium on healthy ageing: topic focus: frailty and intrinsic capacity. Report of consortium meeting; 2016 Dec 1-2 in Geneva, Switzerland. World Health Organization. 2016. URL: https://apps.who.int/iris/handle/10665/272437 [accessed 2021-07-15]

61. World report on ageing and health. World Health Organization. URL: https://apps.who.int/iris/rest/bitstreams/835463/ retrieve [accessed 2021-07-15]

62. Low L, Yap M, Brodaty H. A systematic review of different models of home and community care services for older persons. BMC Health Serv Res 2011 May 09;11:93 [FREE Full text] [doi: 10.1186/1472-6963-11-93] [Medline: 21549010]

63. Eklund K, Wilhelmson K. Outcomes of coordinated and integrated interventions targeting frail elderly people: a systematic review of randomised controlled trials. Health Soc Care Community 2009 Sep;17(5):447-458. [doi: 10.1111/j.1365-2524.2009.00844.x] [Medline: 19245421]

64. Woo J. Frailty, Successful Aging, Resilience, and Intrinsic Capacity: a Cross-disciplinary Discourse of the Aging Process. Curr Geri Rep 2019 Apr 25;8(2):67-71. [doi: 10.1007/s13670-019-0276-2]

65. Irving P. Self-empowerment in later life as a response to ageism. Generations 2015;39:72-77 [FREE Full text] [doi: 10.14361/9783839444221-toc]

66. Chenoweth L, Stein-Parbury J, Lapkin S, Wang A, Liu Z, Williams A. Effects of person-centered care at the organisational-level for people with dementia. A systematic review. PLoS One 2019;14(2):e0212686 [FREE Full text] [doi: 10.1371/journal.pone.0212686] [Medline: 30794651]

67. Fazio S, Pace D, Flinner J, Kallmyer B. The Fundamentals of Person-Centered Care for Individuals With Dementia. Gerontologist 2018 Jan 18;58(suppl_1):S10-S19. [doi: 10.1093/geront/gnx122] [Medline: 29361064]

68. Kim SK, Park M. Effectiveness of person-centered care on people with dementia: a systematic review and meta-analysis. Clin Interv Aging 2017;12:381-397 [FREE Full text] [doi: 10.2147/CIA.S117637] [Medline: 28255234]

69. Livingston G, Huntley J, Sommerlad A, Ames D, Ballard C, Banerjee S, et al. Dementia prevention, intervention, and care: 2020 report of the Lancet Commission. Lancet 2020 Aug 08;396(10248):413-446 [FREE Full text] [doi: 10.1016/S0140-6736(20)30367-6] [Medline: 32738937] 
70. Wang G, Marradi C, Albayrak A, van der Cammen TJM. Co-designing with people with dementia: A scoping review of involving people with dementia in design research. Maturitas 2019 Sep;127:55-63 [FREE Full text] [doi: 10.1016/j.maturitas.2019.06.003] [Medline: 31351521]

71. Provoost S, Lau HM, Ruwaard J, Riper H. Embodied Conversational Agents in Clinical Psychology: A Scoping Review. J Med Internet Res 2017 May 09;19(5):e151 [FREE Full text] [doi: 10.2196/jmir.6553] [Medline: 28487267]

72. Kramer LL, Ter Stal S, Mulder BC, de Vet E, van Velsen L. Developing Embodied Conversational Agents for Coaching People in a Healthy Lifestyle: Scoping Review. J Med Internet Res 2020 Feb 06;22(2):e14058 [FREE Full text] [doi: 10.2196/14058] [Medline: $\underline{32022693}$ ]

73. Luria M, Reig S, Tan X, Steinfeld A, Forlizzi J, Zimmerman J. Re-embodiment and co-embodiment exploration of social presence for robots and conversational agents. 2019 Presented at: DIS 2019 International Conference on Designing Interactive Systems; June 23-28; San Diego, USA p. e-644.

\section{Abbreviations}

ECA: embodied conversational agent

Edited by L Buis; submitted 30.10.20; peer-reviewed by K Moore, V von Wyl; comments to author 07.12.20; revised version received 27.01.21; accepted 10.03.21; published 16.07.21

Please cite as:

Rampioni M, Stara V, Felici E, Rossi L, Paolini S

Embodied Conversational Agents for Patients With Dementia: Thematic Literature Analysis JMIR Mhealth Uhealth 2021;9(7):e25381

URL: https://mhealth.jmir.org/2021/7/e25381

doi: $10.2196 / 25381$

PMID: $\underline{34269686}$

CMargherita Rampioni, Vera Stara, Elisa Felici, Lorena Rossi, Susy Paolini. Originally published in JMIR mHealth and uHealth (https://mhealth.jmir.org), 16.07.2021. This is an open-access article distributed under the terms of the Creative Commons Attribution License (https://creativecommons.org/licenses/by/4.0/), which permits unrestricted use, distribution, and reproduction in any medium, provided the original work, first published in JMIR mHealth and uHealth, is properly cited. The complete bibliographic information, a link to the original publication on https://mhealth.jmir.org/, as well as this copyright and license information must be included. 